Psychosis and Deafness in Forensic Settings: How are Hallucinations and Delusions shaped by Experiences of Being Deaf

\author{
Saffron Morris, David M. Gresswell, and Hannah L. Merdian
}

School of Psychology, University of Lincoln, Lincoln, UK

This paper is published in the International Journal of Forensic Mental Health Doi: $10.1080 / 14999013.2019 .1673518$

Saffron Morris, School of Psychology, University of Lincoln, Lincoln, UK.

Hannah Lena Merdian, School of Psychology, University of Lincoln, Lincoln, UK;

ORCiD: 0000-0003-2030-7694. David Mark Gresswell, School of Psychology, University of Lincoln, Lincoln, UK; ORCiD 0000-0002-0797-5279.

Saffron Morris is now at Community CAMHS West, 3-5 Lindsay Close, Mansfield, Nottinghamshire, NG18 5TF.

Correspondence concerning this article should be addressed to Hannah L. Merdian, School of Psychology, University of Lincoln, Brayford Pool, Lincoln, LN5 7AY, UK.

Email: hmerdian@lincoln.ac.uk 


\section{Psychosis and Deafness in Forensic Settings: How are Hallucinations and Delusions shaped by Experiences of Being Deaf}

Forensic inpatients who experience hallucinations and delusions present with complex clinical needs, which can be exacerbated through additional individual difficulties and disabilities impacting responsivity. Experiences of hallucinations and delusions are shaped by the individual's context and culture; however, to date this has not been explored with regards to the experience of deaf persons. The current study employed Multiple Sequential Functional Analysis to conceptualise the developmental nature of hallucinations and/or delusions in a sample of three Deaf men from a secure specialist Deaf service. No evidence was found of unique experiences shaping the content and themes of hallucinations; however, participants reported a learning history of associating deafness with being inferior, which later emerged in delusions of grandeur. Across all three cases, there was a noticeable lack of clinical information available in case notes and a lack of targeted interventions offered by forensic service providers.

Keywords: deafness; hallucinations; delusions; psychosis; Multiple Sequential Functional Analysis; forensic inpatients 


\section{Introduction}

There is considerable diversity among deaf persons with regards to the degree of deafness, linguistic preferences, and cultural identity. There are two primary models of deafness; the medical model and the cultural model. According to the medical model of deafness, being 'deaf' (lowercase) is viewed as a physiological condition of not being able to hear (Lane, 1992; Marcowicz \& Woodward, 1982). Deafness is therefore framed as a disability needing to be 'fixed' within the medical model and many Deaf people view the medical model as oppressive, due to the emphasis on a pre-determined 'normal' functioning which neglects different types of visual and adaptive functioning used by Deaf persons (MunozBaell \& Ruiz, 2000). By contrast, the cultural model does not depict deafness as a disability of hearing. Instead, being 'Deaf' (capitalised) is viewed as predominance in visual functioning rather than impairment in auditory ability, accompanied by a cultural Deaf identity, which is distinct to their local cultural identity, cultural heritage, and community. The cultural model is often the perspective of those born deaf and who communicate predominantly through sign language (Berke, 2010).

Deaf people have a notably higher lifetime prevalence of mental health issues than the general population (40\% vs. 25\%; Department of Health, 2005; Joint Commissioning Panel for Mental Health \& SignHealth, 2017), and are reportedly more likely to be detained in forensic secure units (Gibbon \& Doyle, 2011). In their review on assessment needs of deaf clients in forensic services, O'Rourke and Grewer (2005) highlighted significant responsivity and service provision issues, including over-assessment of incompetence to plead, vulnerability to diagnostic errors, clinical interviews and offence analysis conducted from a hearing perspective, and non-standardised adjustments of psychometrics and risk assessment tools. Mitchell and Braham (2011) further highlighted significant challenges in the delivery of interventions to deaf offenders. Forensic services 
have been found to be unable to meet the needs of $\mathrm{d} /$ Deaf persons due to limited knowledge of Deaf culture, insufficient and inconsistent provision of interpreters, the inherent social isolation related to limited or no persons to communicate with, and neglect (Gahir, O’Rourke, Monteiro, \& Reed, 2011; Kelly, 2018; McCulloch, 2010; Young, Monteiro, \& Ridgeway, 2000). Unless in a specialised Deaf service, inpatients or prisoners who are deaf may often have difficulty accessing group treatment or targeted interventions, thus failing to fulfil conditions that may be linked to their release or security classification (see Gibbon \& Doyle, 2011; Kelly, 2018). Furthermore, the difficulties encountered by $\mathrm{d} /$ Deaf persons in the forensic system may contribute to the development of mental health difficulties (Kelly, 2018; Young et al., 2000). It is thus crucial to provide guidance for best practice when working with forensic patients who are deaf.

\section{Psychosis and deafness}

The prevalence of psychosis in the $\mathrm{d} /$ Deaf population is difficult to estimate because of barriers to accessing services (e.g., limited specialised Deaf services) and it is often not customary to register hearing status upon admission into general mental health services. To date, only two large scale population studies have investigated prevalence rates of psychosis with deaf persons (Stefanis, Thewissen, Bakoula, van Os, \& Myin-Germeys, 2006; Thewissen et al., 2005). A population-based Dutch study found that hearing loss was associated with an increase of psychotic symptoms at the end of a three year follow up; indeed, adults with a hearing impairment were found to be three times more likely to have psychotic symptoms (Thewissen et al., 2005). Similar findings were shown in a large scale replication study in Greece, where more than 11,000 new-born children were followed up at ages 7 and 19 and deafness was associated with twice the frequency of psychotic symptoms (Stefanis et al., 2006). However, these studies have been criticised for their definition and operationalisation of deafness. For example, in the study by Thewissen et al. 
(2005), deafness was established by a subjective report of whether the participants had experienced deafness or serious hearing loss over the last 12 months at the time of the interview. It is therefore not possible to determine whether the research is representative of individuals who were hard of hearing, had acquired hearing loss in later life or were profoundly deaf since birth, used sign language or held a cultural identity related to their deafness, limiting the generalisation of findings (see Fellinger et al., 2012 for further prevalence information).

The Stress-Vulnerability model (Zubin \& Spring, 1977) proposes that exposure to psychosocial stressors is a key factor in the development of psychosis. For example, being part of a minority group and associated 'social defeat' (i.e. being in a subordinate position or having an outsider status, associated with being a member of a minority community) are psychosocial stressors identified with increased risk of psychosis (see Cantor-Graae \& Pederson, 2007; Selten \& Cantor-Graae, 2005; Veiling et al., 2006). A possible explanation for the increased prevalence of psychotic symptoms in the $\mathrm{d} /$ Deaf population may therefore be an increased exposure to psychosocial stressors (e.g., see Kitson, Fernando \& Douglas, 2000; Valentine \& Skelton, 2007). Deafness may further be linked to social isolation in the family environment, school, and community due to communication difficulties (Greenberg, 2000). Hall, Smith, Sutter, DeWindt and Dye (2018) found that deaf people of hearing parents experienced limited access to contextual learning, a factor indicated in later health outcomes, during their childhood. The social perception of deafness as a disability may also support a negative perception of mental healthcare providers (Glickman, 2008), viewing inpatient units as a place where people who are deaf are abandoned or may be mistakenly admitted by 'prejudiced hearing authorities' (Steinberg, Sullivan, \& Loew, 1998). These social messages can become internalised into core aspects of the individual's self-concept and contribute to mental 
health difficulties (Vernon \& Andrews, 1990). The Stress-Vulnerability model suggests that psychotic symptomatology will only emerge when the individual's threshold of stressors exceeds their vulnerability level (Zubin, Magaziner, \& Steinhauer, 1983). Consequently, deafness in itself is not considered a risk factor for psychosis but may contribute to the increased exposure to psychological stressors throughout the life span.

\section{Cultural influences on hallucinations and delusions}

The limited research investigating deaf persons' experiences of psychosis, particularly delusions and hallucinations, has focussed on their sensory modality and whether it is possible for a deaf person to 'hear' voices (e.g., Atkinson, Gleeson, Cromwell, \& O’Rourke, 2007; Critchley, Denmark, Warren, \& Wilson, 1981; Du Feu \& McKenna, 1999; Pederson \& Nielson, 2013; Schonaeur, Achtergarde, Gotthardt, \& Folkerts, 1998). Atkinson et al. (2007) found that the perceptual characteristics of hallucinations reflected not only the previous auditory experiences of the d/Deaf participants but also the modality of their communication preferences (such as sign language, spoken communication). However, there has not been any rigorous exploration of wider issues, such as the content and the personal meaning ascribed to these experiences, in the context of the $d /$ Deaf person's life.

Hallucinations and delusions are both culturally bound and pathoplastic, meaning that they are formed through and in local expectation and meaning (Laroi et al., 2014). Hallucinations and delusions amongst hearing populations typically reflect the dominant stereotypes, religious beliefs, and concerns of the individual's culture (Kent \& Wahass, 1996; Stompe et al., 2006; Yamada, Barrio, Morrison, Sewell, \& Jeste, 2006), and thus have been found to differ over time (see Maher \& Spitzer, 1993; Mitchell \& Vierkant, 1989) and across cultures (see Kent \& Wahass, 1996; Kim et al., 1993). 
With regards to individuals who are Deaf, it is therefore important to consider how the contextual influences of the Deaf community and living in a 'hearing world' may influence their beliefs. The unique context of Deaf individuals' reality should therefore be given consideration when exploring the nature of their delusions or hallucinations due to the potential differences of their everyday life and circumstances. Moore (2016) identified views that Deaf individuals may behave in ways that are adaptive within their own context despite these not being considered to be adaptive by general society. Participants in the study by Moore implicated experiences of repeated setbacks in attempting day-to-day tasks and adaptive skills (for example complaining) in the development of a passive approach or learned helplessness. These behaviours, which would otherwise be considered to be maladaptive, were proposed to be adaptive in the Deaf individual's context in order to preserve energy when attempts at change will likely yield no change. Deafness may impact on many aspects of the Deaf individual's life. For example, as a hearing individual it is possible to covertly convey a message to someone when in the presence of others by lowering the volume of speech. For a Deaf individual whose language production is physical it is more difficult to have a private conversation as others in their community would be acutely aware of what they were communicating. The physicality of sign language also carries implications for the individual outside of their community. When in a place populated by hearing individuals, who may not frequently see members of the Deaf community having a conversation in sign language, there may be increased social attention. These are specific issues faced by the Deaf community providing a cultural context through which an individual's experiences, view of self, others and the world could be understood and should be explored in relation to their individual experiences of hallucination and delusions. The historical context of Deaf culture and the Deaf community is also important to consider. Within the Deaf community there are beliefs 
reflecting complex issues and the historical context of Deaf culture which may be difficult to understand from a hearing perspective. A key example of this relates to the UK government failing to recognise BSL as a language in its own right until 2003 and that legal status of the language has still not been achieved, impacting on access to information, education and services for Deaf people (British Deaf Association, 2014).

The limited literature available on hallucinations and delusions in d/Deaf persons reflects the wider issue of research concerning the mental health of this group having been criticised for being "behind hearing mental health research by at least forty years" (Glickman \& Pollard, 2013, p. 360). In particular, the investigation of delusional beliefs of $\mathrm{d} /$ Deaf people appears to have received very little attention in the literature. A search of PsycInfo using the terms; Deaf, deafness, hearing disorder, and hearing impairment combined with delusion* and delusional (*indicates truncation) mainly retrieved papers investigating delusions in the context of late onset deafness/ hearing impairment (e.g., Chae \& Kang, 2006; Sommer, Roze, Linszen, \& Zanten, 2014). Only Glickman (2009) provides an account of delusional beliefs of Deaf individuals receiving care on Deaf psychiatric units and reported that delusions of grandeur, such as being a king, being sent special messages or on special missions by God, were common for this group.

The current literature on the psychotic experiences of $d /$ Deaf people has used nomothetic approaches aiming to identify what is shared among this population and to describe the characteristics of hallucinations (e.g., Atkinson, 2005; Atkinson et al., 2007; du Feu \& McKenna, 1999). However, in order to understand the experience of psychotic symptoms in deaf clients, and to work with them effectively, it is vital to investigate how the individual's unique learning history, the shared experience of being $\mathrm{d} /$ Deaf, and the wider impact of Deaf culture may shape and maintain these symptoms.

\section{Current research}


Given the above, a greater understanding of common psychosocial factors, and their role in shaping the content of hallucinations and delusions for Deaf individuals, is crucial in guiding clinical practice. As a response to the significant gap in the professional practice literature, the aim of the current study was to track the developmental nature of hallucinations and/or delusions in a sample of Deaf adults within their unique learning history, in order to inform, and standardise, current clinical practice. A Multiple Sequential Functional Analysis (MSFA) framework was used to answer two main research questions:

1. What are the themes, topography, and content of hallucinations and delusions amongst a sample of Deaf adults diagnosed with psychosis?

2. How have the themes, topography and content of hallucinations and delusions been shaped by the individual's developmental history and the experiences which are unique to being Deaf and Deaf culture?

\section{Methodology}

\section{Design}

The study employed a systematic case study design; this provides a bottom-up approach to evidence based practice (Fishman, 2005), allowing for the investigation of shared themes and processes across cases (Iwakabe, 2005; Iwakabe \& Gazzola, 2009). Case studies have previously been used for investigating experiences of psychosis with $d /$ Deaf individuals (Pederson \& Nielson, 2013; Weiler, Landsberger, \& Diaz, 2013). This approach therefore allowed for a detailed assessment of each individual case in order to explore the developmental context of their hallucinations and delusions (Bywood, Gresswell, Robertson, \& Elwood, 2006; Corbin \& Strauss, 2008). The study was granted ethical approval by the host university, and relevant public health authority Research and Ethics Committee.

\section{Participants}


Participants were recruited from a Secure Specialist Deaf service via their care team using a consecutive recruitment strategy. Deaf individuals were able to participate in this study if they were aged over 18 years, with a diagnosis of any psychotic disorder, and self-reported experiences of hallucinations and/or delusions. Participants were required to have a pre-lingual deafness and use British Sign Language as their primary mode of communication. All participants were required to have capacity to consent as assessed by a senior clinician in the service.

Although a written participant sheet had been provided, considerations were also made for the population that was recruited with regards to the varied written English ability of the adult d/Deaf population; an interpreter was present as it was expected that participants may not have the literacy skills to read the information sheet and consent form. The interpreter present signed the consent form stating that they had translated the information detailed in the document and that the participant had agreed to take part in the study; this process was witnessed by a third party.

A minimum sample size of three was desired to allow for the data richness required for exploratory qualitative research. This is supported by the existing literature of studies employing MSFA that has established the efficacy and appropriateness of using small sample sizes (Dawson \& Gresswell, 2010; Gresswell \& Hollin, 1992; Mappin, Dawson, Gresswell, \& Beckley, 2013). The final sample comprised of three male participants, aged 37-51 years (see Table 1 for demographic information).

[insert Table 1 about here]

\section{Data collection and procedure}

Three sources of information were obtained for each individual. The primary data were gleaned from two interviews with the participant; this was then triangulated with supplementary data from a file review and a supporting interview. 


\section{Participant interviews}

Two semi-structured interviews were conducted for each participant by the lead researcher, supported by a sign language interpreter, lasting one hour each. The interviews were video-recorded to support accurate documentation of the participants' own accounts. Video-recording was selected due to the visual nature of BSL as traditional dictaphone recording would only have documented the mediated transactions between researcher and interpreter meaning that the original accounts of the participants would be lost (KellyCorless, 2019) and authenticity of the data would be solely reliant on the translations of an interpreter (Kelly, 2017; Kelly-Corless, 2019). Methodological recommendations for qualitative research with interpreters were followed to strengthen the trustworthiness of the data, including establishing the translator's qualifications/ prior experience, confidentiality, and their role within the process (Squires, 2009). An interpreter was sought who had experience of working within the service to ensure that they were experienced in working within the confidentiality framework of healthcare. The interviews explored the individual's current experiences and developmental history of hallucinations/ delusions to provide the framework for an MSFA analysis (see Mappin et al., 2013). The interviews also explored the participant's wider developmental history to allow for sufficient information to generate a detailed case formulation across the participant's lifespan (Sturmey, 1996, 2008), including; childhood, education, friends, family and intimate relationships. Psychosocial factors that are associated with psychosis, identified from the existing hearing literature (e.g., experience of trauma) were also explored, alongside the individual's exposure to the Deaf community/ culture and sign language. Due to the sample recruited all having a forensic history, their offence history was also explored on an individual basis in the second interview where this was considered to be relevant to the developing MSFAs. 


\section{File review}

A file review of the individual's clinical records was conducted to gather collateral information about the individual's hallucinations and delusions (i.e., type, content, severity and onset) and any significant events reported in the interviews. There was a vast amount of documents and records about each participant due to the number of years that they had been within secure psychiatric services; a total of 113 records were reviewed across the cases (see Table 2 for a summary of documents reviewed).

$$
\text { [insert Table } 2 \text { about here] }
$$

\section{Supporting interviews}

Participants were asked to identify either a professional or relative who had a good knowledge of their history for a supporting interview. Each participant identified their consultant psychiatrist. As all participants had the same consultant psychiatrist, one professional completed all the supporting interviews (ranging from 30-60 minutes). The professional interview was semi-structured and aimed to explore areas that needed clarification arising from the participant interviews.

\section{Data analysis}

The data analysis was conducted in two stages: (1) an analysis of the individual case histories, and (2) across-case analysis in order to identify any common psychosocial factors and their role in shaping the content of hallucinations and delusions for Deaf individuals.

\section{Stage 1: Individual case analysis}

Multiple Sequential Functional Analysis (MSFA; Gresswell \& Hollin, 1992) is a qualitative case history methodology that was developed to understand the function of behaviour within a developmental context. Within a functional analysis paradigm (see Sturmey, 1996), a three-part, Antecedent, Behaviour, and Consequences (A:B:C), analysis is applied to the 
behaviour of interest (Bijou, Peterson, \& Ault, 1968). MSFA extends the typical functional analysis to account for the role of learning on the maintenance of behaviour and can be placed within the theoretical framework of functional contextualism (Hayes, 1993). An MSFA sequence is considered 'valid' if it informs effective action (e.g., through the construction of practical knowledge; Biglan \& Hayes, 1996; Fox, 2006; 2008). This identifies MSFA as a suitable methodology for small sample-research, where no prior research is available to guide the analysis framework. Although in MSFA covert behaviours are distinguished from observable (overt) behaviours, they are viewed to be developed and maintained in the same manner, through interaction with and reinforcement from the environment (Skinner, 1974). Complex chains of behaviours are produced by considering the key learning history at each stage of the analysis, resulting in the consequence of one $A: B: C$ sequence becoming the antecedent of a subsequent $A: B: C$ sequence. This method has previously been used to assess an individual's developmental history and behaviour when they have a diagnosis of psychosis (Dawson \& Gresswell, 2010), and with complex forensic case material (Gresswell \& Hollin, 1992).

MSFA was therefore used in Stage 1 of the analysis to develop a greater understanding of the unique learning history of each individual case. The triangulation of multiple data sources is an inherent component of MSFA (Gresswell \& Hollin, 1992), in order to reduce the possibility of bias (Denzin, 1989) and to enrich the participant's introspective account with data from other sources (Emerson, 1981; Jupp, 1989; Webb, 1966).

Cumulative information gathered for each individual was used to develop a coherent narrative of the participant's developmental history. Any identified discrepancies between data sources were scrutinised to establish the account which was considered to be more reliable, either by identifying collateral evidence supporting the account or in instances when this was unavailable by identifying the account that was the most 
consistent. Following this, MSFA sequences were developed to allow for an idiosyncratic developmental formulation of the experiences of hallucinations and/or delusions for each individual. Regular discussions with research supervisors were held throughout the analysis process in order to reduce the potential for researcher bias.

Stage 2: Across-case analysis

The second stage of analysis involved an across-case analysis of the MSFA sequences employing thematic analysis in order to provide an understanding of any common factors across the sample, and to explore how the identified themes related to experiences of hallucinations and delusions across the developmental histories. While this process is often conducted in an unstructured manner, thematic analysis was employed here as it offers a systematic and structured framework for analysing large data sets and exploring the perspectives of different participants in order to identify similarity, differences and common themes (Braun \& Clarke, 2006; King, 2004). Inductive Thematic Analysis (TA; Braun \& Clarke, 2006) was used to provide a systematic framework for identifying common themes across the MSFA sequences, by following a six phase approach: (1) familiarizing yourself with your data; (2) generating initial codes; (3) searching for themes; (4) reviewing themes; (5) defining and naming themes; and (6) producing the report. Although these stages are presented as a linear process, TA involves a process of moving back and forth between the phases.

Phases 1-3. In the familiarisation phase, the interviews with participants were watched and re-watched, and the interview notes, the developed MSFA sequences, and the file reviews were read a number of times. During this process, initial aspects of the data that were of interest, captured a distinct feature of the data, and appeared to have relevance to the research aims were coded. The initial codes were colour coded and grouped according to identified connections to develop emerging themes. 
Phases 4-6. Emerging themes were restructured as changes to the groupings of codes were made dependent on new links that were established through the data, and whether themes were thought to accurately represent the codes. This process involved the reorganisation and clustering of themes into superordinate and subordinate themes to identify the final key themes to be defined and named. The final process of the analysis concerned the write up of the report and presentation of the themes in the result section.

\section{Results}

\section{Stage 1: Individual Case Analysis}

For each individual, a MSFA was created for the different developmental phases identified though the data, such as school entry or onset of psychotic symptoms. For the purpose of this paper, three MSFA sequences have been selected; school, early onset of psychosis, offence behaviours and experiences of secure psychiatric services (Tables 3-6), to highlight the research process and the development of external attributional styles leading to paranoia, helplessness, or grandiosity (depending on the individual) through reinforcement and punishment contingencies. The full set of MSFAs for each case can be accessed on the Open Science Forum (please contact the authors).

[Insert tables 3-6 about here]

\section{Case Summary: Ben}

Ben was born into a hearing family; he was hearing at birth but lost his hearing aged two years due to meningitis, which also resulted in a two month hospital admission. As his mother was pregnant during his hospital stay, she was unable to visit him. His transition back home was difficult due to communication barriers with his hearing parents and siblings.

The analysis of Ben's learning history resulted in six MSFA sequences; childhood experiences; "prodromal" experiences; early onset of psychosis; coping in the community; 
high secure psychiatric service; and access to Deaf services. His MSFAs highlight a sense of persecution and powerlessness developing throughout his life that had been shaped by his perception of disadvantage and discrimination in relation to his deafness. For example, resulting from his experience at a Deaf residential school, Ben developed a relational frame $^{1}$ within which deafness was paired negatively with 'stupidity', as he perceived needing to use sign language as intellectually inferior to using oral communication, and subsequently he appeared to develop an identity conflict about belonging to either the Deaf or hearing communities. His exclusion from family life due to communication barriers appeared to have shaped his sense of paranoia and suspicion in relation to his belief that he is ignored. This sense of being disadvantaged continued through his life; for example, while in prison, when he informed staff of his isolation, the prison suggested he improved his ability to communicate with another deaf prisoner rather than adapting their ability to communicate with him. The poor support provided and negative affect he experienced in relation to his help-seeking attempts decreased future help-seeking behaviours and contributed to the development of passivity and learned helplessness.

His offence behaviours appeared to have been reinforced through two different contingencies; it is positively reinforced through the sense of power, control and achievement he experienced and pride of getting away with the first arson. In addition his offence behaviours were negatively reinforced through the removal of his financial difficulties. Returning to an institutional setting may have provided him with the containment and structure he had when at residential school. It is hypothesised that the

\footnotetext{
${ }^{1}$ A relational frame refers to the pairing of stimuli whereby connections are derived between the stimuli that have the ability to change the nature or function of the stimuli (Hayes, Barnes-Holmes, \& Roche, 2001).
} 
sense of containment that being in an institutional setting provided him may have reinforced his sense of not being able to work his own way out of his negative circumstances without going into prison/ psychiatric services.

It is hypothesised that his offence behaviours were negatively reinforced when he returned to prison. The reason for this being that he had been distressed about not being able to cope on his own in the community, therefore this distress is hypothesised to have reduced once he returned to prison. However, his sense of helplessness also appeared to be reinforced as he had no sense of agency in how to improve his circumstances other than returning to institutional settings and he therefore locates control externally.

\section{Case Summary: Michael}

While Michael is the only child from his mother's relationship with his biological father, he has eight older siblings from his father and two younger siblings from his mother's second marriage. Michael is the only deaf person in his family and he experienced communication barriers in the home environment as a result of this.

Michael's learning history was captured in seven MSFA sequences: early childhood experiences; victimisation; introduction to Deaf culture; "prodromal experiences"; early onset psychosis; index offense; and secure psychiatric services. They highlighted delusions of grandiosity, suspicion, and feelings of persecution that developed throughout Michael's life. Michael reported experiences of being disadvantaged (e.g., by having to go to residential school due to being deaf) and victimised (e.g., being bullied by local 'youths' who insulted him for being deaf and would take his hearing aids out), and described a sense of conflict about which group he belongs to (Deaf or hearing). These experiences appeared to shape his paranoia in relation to delusions of persecution and collusion against him, which was reinforced by non-supportive staff attitudes in the institutions he attended. Michael's account revealed that he associated deafness with 
disability and with 'being weak and inferior': the development of delusions of grandeur served to protect him from those feelings of inferiority along with the development of an attributional style, locating blame for his failures externally. His grandiosity is also hypothesised to have been positively reinforced by the media coverage following his index offence.

\section{Case Summary: Aiden}

Aiden is one of three siblings; he has an older brother who is also deaf, with whom he could communicate by sign language. Furthermore, in contrast to the other participants, his mother and sister also learned sign language and attended a local Deaf club with Aiden and his brother: a marked difference to the other participants whose families could not communicate.

The analysis resulted in seven MSFA sequences for Aiden; early experiences; receiving a cochlear implant; attempts to be independent; prodromal; early onset of psychosis; admission to psychiatric services; and decisions made by professionals to transfer Aiden to a new psychiatric service. For Aiden, the MSFAs also highlighted a sense of grandiosity, specifically in relation to inventions and having superior knowledge to others. This was understood to have been shaped through his experiences of being involuntarily grouped with other deaf individuals who he perceived as having lower intelligence and communication proficiency than him. Aiden's interest in science was negatively reinforced through the removal of the perceived threat of being bullied and disconfirmation of his worries of being perceived as 'stupid' as other deaf people. His experiences at school created the foundation of specialist knowledge in science as a protective factor, which later developed into grandiosity and delusions of special scientific knowledge. By contrast, Aiden's paranoia and sense of persecution appeared to have been shaped by experiences of disadvantage and physical abuse. Aiden reported that he was raped by a man after going to 
a nightclub when he was aged 20 years; this was a significant learning event that further impacted on his sense of persecution and gave rise to paranoid beliefs that other patients were homosexuals and wanted to assault him.

Aiden was fitted with a cochlear implant when he was 12 years old and subsequently felt rejected by the Deaf community. His perception of not being supported with his implant appeared to be important in shaping his paranoia, learned helplessness, and delusional beliefs, specifically about his cochlear implant making him identifiable as a deaf man and of society being against him.

His learned helplessness is hypothesised to have developed when his first attempt to seek help was unsuccessful, he felt unsupported and that it was not worth asking for help as it would not be provided. Help seeking behaviour is therefore thought to have decreased due to the perceived rejection from the audiology department (punishment). He changed his strategy to retaliate against those who he believed had wronged him, this led to his arrest and admission to a psychiatric service. Although this would be expected to decrease the behaviour through positive punishment, his arrest also met his goals of removing him from his environment and he believed he had 'made a statement' about his anger towards the audiology department. Therefore his behaviour of making bombs was seen to be positively reinforced as this is a behaviour seen later in his journey through forensic services.

\section{Stage 2: Across-Case Analysis}

\section{Content of the reported delusions and hallucinations}

The study was able to identify the topography of hallucinations and some depiction of common themes; however, the analysis was limited by a lack of content available regarding hallucinations. More information was available regarding experiences of delusions: both Michael and Aidan reported delusions of grandeur relating to having special knowledge or abilities. There was also a common theme across the participants of 
paranoia related to being targeted or disadvantaged. The individual's language history appeared to influence the topography of their hallucinations; indeed, Ben and Michael experienced hallucinations in the form of visual images and sensations reflecting their visual mode of communication. Aiden was the only participant who experienced any auditory hallucinations, reflecting his hearing and language history.

Despite the details given above the lack of information regarding the content of hallucinations and delusions across all of the participants made it difficult to develop hypotheses related to how the form of the experiences had been shaped by their context and developmental history. This difficulty was linked to difficulties encountered during the analysis process in relation to missing information and inconsistencies/ incoherence in the narratives of participants. It appeared that for all three cases psychological interventions were predominantly group based with different psycho-educational remits. Although all the participants had received individual psychological interventions, these were focussed on their offence behaviours while their experiences of hallucinations and delusions, which in all cases were documented in their records to have been thought to be functionally related to their offending behaviours, did not appear to have been explored.

\section{Thematic Analysis}

A total of 20 MSFA sequences were created across all three cases. Cross-case analysis identified seven key themes (see Table 7).

\section{[insert Table 7 about here]}

The across-case analysis highlighted three key findings. Firstly, the TA identified a number of shared themes that were seen to interact with deafness; namely, acceptance of deafness as a negative state; caught between two worlds; deaf-specific victimisation; language factors; and service access issues. For example, one subtheme emerging in "Acceptance of deafness as a negative state" was linked to a feeling of powerlessness 
experienced by participants across their learning histories, related to actual and perceived limited control in their lives because of their deafness. Aiden directly commented on his perception that he had "not had the opportunities to do the same things as hearing", a sentiment reflected by the other participants and it appeared that their perceived limited control and power influenced the development of learned helplessness, particularly in relation to withdrawal from society and passivity. However, while these themes were reflected in the experiences of hallucinations and delusions, for example Ben's paranoia or Aiden's belief that he was followed and targeted by homosexual males, this appeared to occur through more general psychosocial mechanisms, such as a response to trauma/ abuse and social defeat. Furthermore, all three participants reported the experience of an identity conflict (i.e., Caught between two worlds), and appeared to have made a negative pairing of deafness and inferiority, starting during their schooling and maintained throughout their life. These negative associations with deafness and the related identity conflict are likely to have influenced delusions of grandeur related to having or developing special abilities, status, and/or knowledge.

On the other hand, there were themes identified across all the participants that did not relate specifically to unique experiences of being Deaf; general victimisation and common psychosocial factors. The impact of deafness on the participants' experiences of hallucinations was predominantly in the context of victimisation and social disadvantage; for example, the reported "voices" were experienced as "derogatory", "negative" and "embarrassing and personal", indicating that the participants' learning histories of being humiliated, discriminated against, and targeted may have shaped the hallucinatory content.

\section{Discussion}

The current study aimed to explore delusions and hallucinations within the context of unique experiences of being deaf and being exposed to Deaf culture. The findings 
indicate that the individual's learning histories shaped their experiences of delusions, identifying a common theme of paranoia related to being targeted or disadvantaged. All participants included in the study had an offence history. Offence behaviours appeared to be associated to feelings of vulnerability, abandonment, anger and loneliness in addition to substance use, reflecting the known schema modes associated with offence behaviours and institutional transgressions (Kleuen de-Vos et al., 2016). However, in line with the analysis framework of this study, offence behaviours were not highlighted as a particular focus of the analysis unless there was considered to be a direct relationship between the hallucinations and/ delusions held by the individual.

The paranoid delusional beliefs of one participant, Aiden, concerning the government conspiring to control him through his cochlear implant demonstrated the strongest link between the experience of being deaf and the content of a delusional belief. This delusional belief appeared to have been shaped by: his experience of rejection from the Deaf community after he was fitted with the device, his perception of being recognised as a deaf person because of the scar, attribution of blame towards the device for not being able to find employment, and perception of being unsupported by hearing services. Furthermore, specific experiences of being d/Deaf were also found to influence the themes and content of delusional beliefs in response to negative parings between deafness and disability/ stupidity. Interestingly, for two participants, their experiences of social isolation appeared to be linked to their fight against being perceived as stupid or weak and was closely related to a theme of having special abilities/ knowledge in relation to delusions of grandeur. These findings are consistent with Glickman's observation that delusions of grandeur ("being special") are common delusional beliefs among Deaf people in psychiatric units (Glickman, 2009). 
The individual's language history appeared to influence the topography of their hallucinations; however, there was no evidence of unique experiences of being Deaf or Deaf culture influencing the content of hallucinations. The form of voice hallucinations were found to relate to the individual's language and communication history as found by Atkinson et al. (2007): Ben and Michael, both born deaf, experienced voices as bodily sensations and visual images, while Aiden, the only participant with a hearing/ language history (due to being fitted with a cochlear implant), reported auditory hallucinations. It therefore appeared to be primarily the individual's language and communication history that shaped the topography of their hallucinations. Other than that, it appeared that hallucinatory content was shaped by the general experience of being victimised and socially disadvantaged, common psychosocial stressors that are shared with the hearing population and not unique to being Deaf. Research has found that stressful life events including victimisation and social defeat are associated with increased incidence of psychosis (Bebbington et al., 2004; Lataster et al., 2006; Selten \& Cantor-Graae, 2005; Thompson et al., 2014). It may therefore be that experiences of being Deaf in the context of hallucinations can be best understood within the Stress Vulnerability Model as psychosocial stressors (Zubin et al., 1983).

However, the above analysis was limited due to difficulties encountered in the data collection and analysis process. One of the most noteworthy findings of the current study was the difficulty in accessing the content of delusions and hallucinations of the participants in both the interview process and the documentation. It was evident that professionals directly involved in assessing the participants during their time in psychiatric services had had the same issue thus indicating that this was not a direct result of the research interview method. This finding raised the questions about the ability of $d / D e a f$ psychiatric patients to access and communicate their internal experiences and how 
psychiatric services may have supported or restricted participants' abilities to understand and express those experiences. It is important to note that the file reviews identified that all participants had been assessed to have normal cognitive functioning. Therefore the finding regarding participants' difficulties in communicating their internal experiences should not be attributed to any intellectual disabilities and the difficulties encountered in the current study are the result of a factor separate to an explicit cognitive impairment.

In reviewing the available case material, two hypotheses were highlighted. Firstly, the participants hold an understanding of their experiences of hallucinations or delusions but sharing this understanding with the researcher and professionals involved in their care has been impeded by assessments using a 'traditional' (hearing-developed) interview processes. . The limited information available on content may also have been impacted by difficulties in constructing and sequencing narratives that were observed during the interviews with participants in this study. Previous educational based research with deaf children has identified difficulties in time perception and organising a coherent narrative (Kaiser-Grodecka \& Cieszynska, 1991; Marschark et al., 2002; Pakulksi \& Kaderavek, 2001) but these may be cognitive skills that ordinarily develop in later adolescence or adulthood. Glickman and Hall (2019) suggest that language deprivation may be one factor that impacts on an individual's ability to produce a coherent narrative, two of the three participants could be considered to have experienced early language deprivation. It is therefore unclear how the identified process-related issues may have impacted on the data collection and analysis of content. Further research is clearly needed to investigate whether there is a presence of, and the potential impact of, difficulties in time perception and constructing a narrative on the therapeutic process for $\mathrm{d} /$ Deaf adults. This could inform best practice recommendations to support clinicians to work effectively and collaboratively with $\mathrm{d} /$ Deaf clients. 
Secondly, it may be that the language deprivation/ communication barriers and the structure of care provided by secure psychiatric services has impacted the clients' ability to develop a framework for understanding and communicating their internal experiences. Skinner $(1957 ; 1974)$ outlined the importance of language and communication in order for individuals to learn the importance of their behaviours (including thought and emotions) and to develop self-descriptive behaviours of communicating inner experiences based on the responses of others.

It is therefore possible that Michael and Ben did not develop a framework for understanding and communicating their inner experiences due to the language deprivation they experienced until they attended school and their continued experiences of living in a non-signing environment when at home. The lack of sufficient exposure to any language during childhood development can lead to language dysfluency as well as limited abstract reasoning abilities (Glickman \& Hall, 2019).

However, Aiden was also unable to provide information related to the content of his hallucinations, indicating that this finding was not fully dependent on the individual's communication ability and language history. This highlighted that there may be further factors impacting on the participants' ability to understand and communicate their experiences of hallucinations and delusions. It was hypothesised that the medical model of the forensic psychiatric system may therefore also have played a role in the participants' difficulties in communicating these experiences.

Currently, forensic psychiatric service are typically structured by the medical model, which is focused on the presence/ absence of symptoms within a diagnostic category, therefore reducing the need to explore the individual meaning and content of the hallucinations and delusions. Thus, the care these clients received within forensic settings may have played a role in the continued limited understanding and communication of the 
content of their experiences. Furthermore, it was evident from the client notes that the secure psychiatric services focussed care provision, with regards to psychiatric and psychological input, on offence behaviours rather than their experiences of, and distress related to, hallucinations and delusions. The structure and focus of the psychiatric services in which the participants were receiving care could therefore have restricted the opportunities to explore the individual content and personal meaning of their hallucinations and delusions and prevented the development of a framework to understand and communicate their experiences. Previous research with hearing participants who hear voices has indicated dissatisfaction with the limited range of frameworks facilitated by mental health services through which they can understand their voices (Coffey \& Hewitt, 2008). It is unclear whether Deaf individuals in secure services share these views. It is generally accepted in mental health of hearing persons that an individual's feelings and associated behaviours are thought to reflect the content of hallucinations and that it is through the content and individual meaning assigned to these experiences that otherwise incongruous responses and behaviour can be understood (Chadwick, Birchwood, \& Trower, 1996; Strauss, 1991). However, the finding that accessing the content of these experiences was not possible in this study despite the individuals' current communication ability and communication history indicated that there may be additional factors limiting the access to content. Indeed, all the participants had been heavily observed in psychiatric services over a period of 13-25 years, and the case files contained detailed history and context surrounding the participants' offence behaviours. This supports the hypothesis that participants would be able to provide a greater level of contextual information when this is supported by professionals, enabling them to develop a framework for understanding and communicating the behaviour within context.

\section{Limitations}


All the participants in this study were male; the male sample bias means that any unique experiences of Deaf women have not been accounted for within the current study. Thus, this study would benefit from being replicated with Deaf people of any gender and potentially from non-secure psychiatric services.

Secondly, the use of a sign language interpreter brings with it several issues relating to confidentiality, reliability of translation, and defining the roles of the interpreter and researcher. Despite the limitations of using interpreters, research in minority communities has established the use of interpreters with other cultures and has demonstrated the ability to conduct successful qualitative research with interpreters (Kapborg, 2000; Pavlish, 2005; Woo \& Twinn, 2004). The limitations inherent to using an interpreter were given great consideration. Confidentiality and role identification were explicitly addressed in the interpreter disclaimer form and steps were taken to strengthen the reliability of translation by ensuring the interpreter had a high level of proficiency in both BSL and English (Twinn, 1997).

\section{Clinical Implications}

This study has been able to contribute to the limited literature for the Deaf population and has identified MSFA as a feasible method of analysis for research with Deaf clients and in complex case presentations. A number of clinical implications and areas for future research were identified through the process-related issues encountered in this study.

Firstly, research comparing the care provision for hearing and Deaf psychiatric inpatients with regards to the type of interventions provided have been highlighted as a valuable area of investigation. Unless in a specialised service, deaf inpatients or prisoners may often have difficulty accessing group treatment or targeted interventions, thus failing to fulfil conditions that may be linked to their release or security classification (see Gibbon 
\& Doyle, 2011).In addition, even though all participants in the current study were in specialist Deaf secure psychiatric services, it appeared that difficulties remained with regards to their ability and access to engage in treatment. The focus should be less on comparability of the type of intervention received but whether both groups have the same opportunities to receive the interventions recommended for their difficulties and needs.

The finding that there was a lack of information regarding the content of hallucinations and delusions for all three participants in this study highlights an important issue in the current psychiatric care provision for Deaf persons. It needs to be better understood how Deaf individuals in psychiatric services can be supported to understand and communicate their inner experiences. In order to deliver the standards of personcentred care, clinicians need to develop a contextual framework for the individual's experiences and related distress that acknowledges the content, their culture, and community.

Furthermore, the finding that content was difficult to access not only for this research but also by professionals that had been involved in the participants' care spanning 13-25 years, indicates considerable implications for the assessment and diagnosis of psychosis in this population. Typically, clinical assessment methods rely on verbal content and have been standardised on hearing populations, providing limited resources for clinicians working with Deaf clients (Pederson \& Nielson, 2013). Difficulties in being able to gather detailed information about the individual's experiences of clinical symptoms would be assumed to have a considerable impact on their ability to accurately diagnose a psychosis disorder. This may account for the fact that Deaf individuals are most likely to receive the diagnosis of a psychotic disorder unspecified than any other psychotic disorder, demonstrating the difficulty for clinicians in assessment and diagnosis in the Deaf clinical population (Cole \& Zdanowicz, 2010). Difficulties in understanding the inner experience 
are especially concerning with the current population, as it appeared that the participants' experiences of hallucinations and delusions were causally related to their offending behaviours, thus without a detailed understanding of these experiences and their specific content, the ability to accurately assess risk of future offending therefore appears to be limited. 


\section{References}

Atkinson, J. R. (2006). The perceptual characteristics of voice-hallucinations in deaf people: Insights into the nature of subvocal thought and sensory feedback loops. Schizophrenia Bulletin, 32(4), 701-708. doi: 10.1080/13546800701238229

Atkinson, J. R., Gleeson, K., Cromwell, J., \& O'Rourke, S. (2007). Exploring the perceptual characteristics of voice-hallucinations in deaf people. Cognitive Neuropsychiatry, 12, 339-361. doi:10.1080/13546800701238229

Bebbington, P. E., Bhugra, D., Brugha, T., Singleton, N., Farrell, M., Jenkins, R., ... Meltzer, H. (2004). Psychosis, victimisation and childhood disadvantage. Evidence from the Second British National Survey of Psychiatric Epidemiology. British Journal of Psychiatry, 185, 220 -226. doi: 10.1192/bjp.185.3.220

Berke, J. (2010). Deaf Culture - Big D Small D. Retrieved from http://deafness.about.com/cs/culturefeatures1/a/bigdorsmalld.htm

Biglan, A., \& Hayes, S.C. (1996). Should the behavioural sciences be more pragmatic? The case for functional contextualism in research on human behaviour. Applied and Preventative Psychology, 5, 47-57. doi: 10.1016/S0962-1849(96)80026-6

Bijou, S. W., Peterson, R. F., \& Ault, M. H. (1968). A method to integrate descriptive and experimental field studies at the level of data and empirical concepts. Journal of Applied Behavior Analysis, 1(2), 175-191. 191. doi:10.1901/jaba.1968.1-175

Braun, V. \& Clarke, V. (2006). Using thematic analysis in psychology. Qualitative Research in Psychology, 3(2), 77-101. doi: 10.1191/1478088706qp063oa

British Deaf Association (2014). Legal status for BSL and ISL: Discussion paper. Retrieved from: https://bda.org.uk/wp-content/uploads/2017/03/BDA_Legal-statusof-BSL-ISL_11-Mar-2014.pdff 
Bywood, L., Gresswell, D., Robertson, C., \& Elwood, P. (2006). A behavioural versus a cognitive analysis of the relapse prodrome in psychosis. In J. Johannessen, B. Martindale, \& C. J. (Eds.), Evolving Psychosis (pp. 81-104). London: Routledge.

Cantor-Graae, E. \& Pedersen, P. (2007). Risk of schizophrenia in second-generation immigrants: A Danish population-based cohort study. Psychological Medicine, 37, 485- 494. doi: 10.1017/S0033291706009652

Chadwick, P., Birchwood, M., \& Trower, P. (1996). Cognitive therapy for delusions, voices and paranoia. Chichester: Wiley.

Chae, B., \& Kang, B. (2006). Quetiapine for delusional jealousy in a deaf elderly patient. International Psychogeriatrics, 18(1), 187-188. doi:10.1017/S1041610206283479

Coffey, M., \& Hewitt, J. (2008). "You don't talk about the voices": Voice hearers and community mental health nurses talk about responding to voice hearing experiences. Journal of Clinical Nursing, 17(12), 1591-1600. doi: 10.1111/j.13652702.2007.02185.x.

Corbin, J., \& Strauss, A. (2008). Basics of qualitative research: Techniques and procedures for developing grounded theory (3rd ed.). London: Sage Publications.

Critchley, E., Denmark, J., Warren, F., \& Wilson, K. (1981). Hallucinatory experiences of profoundly deaf schizophrenics. The British Journal of Psychiatry, 138(1), 30-32. doi: 10.1192/bjp.138.1.30.

Dawson, D., \& Gresswell, D. (2010). Offence paralleling behaviour and multiple sequential functional analysis. In M. Daffern, L. Jones, \& J. Shine (Eds.), Offence paralleling behaviour: A case formulation approach to offender assessment and intervention (pp. 89-104). Chirchester: John Wiley \& Sons.

Denzin, N. (1989). The research act: A theoretical introduction to sociological methods ( $3^{\text {rd }}$ ed.). Englewood Cliffs, NJ: Prentice Hall. 
Department of Health (2005). Mental Health and deafness: Towards equity and access. London, UK: Department of Health. Retrieved from http://webarchive.nationalarchives.gov.uk/20130124065527/http://www.dh.gov.uk/ prod_consum_dh/groups/dh_digitalassets/@dh/@en/documents/digitalasset/dh_41 04005.pdf

Douglas, K. S., Hart, S. D., Webster, C. D., Belfrage, H., Guy, L. S., \& Wilson, C. M. (2014). Historical-Clinical-Risk Management-20, Version 3 (HCR-20V3):

Development and overview. International Journal of Forensic Mental Health, 13(2), 93-108. doi: 10.1080/14999013.2014.906519

Du Feu, M., \& McKenna, P. J. (1999). Prelingually profoundly deaf schizophrenic patients who hear voices: A phenomenological analysis. Acta Psychiatrica Scandinavica, 99, 453-459. doi:10.1111/j.1600-0447.1999.tb00992.x

Emerson, R.M. (1981). Observational field work. Annual Review of Sociology, 7, 351-378. Doi: 10.1146/annurev.so.07.080181.002031

Fellinger, J., Holzinger, D., .... Pollard, R. (2012). Mental health of deaf people. Lancet, 379, 1037-1044. doi:10.1016/S0140-6736(11)61143-4

Fishman, D. B. (2005). Editor's introduction to PCSP-From single case to database: A new method for enhancing psychotherapy practice. Pragmatic Case Studies in Psychotherapy, 1, 1-50. Doi: http://dx.doi.org/10.14713/pcsp.v1i1.855

Fox, E. J. (2006). Constructing a pragmatic science of learning and instruction with functional contextualism. Educational Technology Research and Development, 54(1), 5-36. Doi: http://dx.doi.org/10.1007/s11423-006-6491-5

Fox, E. J. (2008). Contextualistic perspectives. In J. M. Spector, M. D. Merrill, J. van Merriënboer, \& M. P. Driscoll (Eds.), Handbook of research on educational 
communications and technology (3rd ed.). (pp. 55-66). Mahwah, NJ: Lawrence Erlbaum Associates.

Gahir, M., O’Rourke, S., Montiero, B., \& Reed, R. (2011). The unmet needs of Deaf prisoners: A survey of prisons in England and Wales. International Journal on Mental Health and Deafness, 1(1), 58-63.

Gibbon, S. \& Doyle, C. (2011). The development and future of deaf forensic mental health services. British Journal of Forensic Practice, 13(3) 191-196. doi: $10.1108 / 14636641111157832$

Glickman, N. (2008). Cognitive behavioral therapy with deaf and hearing persons with language and learning challenges. New York: Routledge.

Glickman, N. (2009). Cognitive behavioural therapy for Deaf and hearing persons with language and learning challenges. New York: Routledge.

Glickman, N., \& Hall, W.C. (2019). Language deprivation and deaf mental health. New York: Routledge.

Glickman, N., \& Pollard, R. (2013). Deaf mental health research. In N. Glickman (Ed.), Deaf mental health care (pp. 358-379). New York: Routledge.

Greenberg, M. (2000). Educational interventions: Prevention and promotion of competence. In P. Hindley \& N. Kitson (Eds.), Mental health and deafness (pp. 311-336). London: Whurr Publishers Ltd.

Gresswell, D., \& Hollin, C. (1992). Towards a new methodology for making sense of case material: An illustrative case involving attempted multiple murder. Criminal Behaviour and Mental Health, 2, 329-341.

Hall, W.C., Smith, S.R., Sutter, E.J., DeWindt, L.A., Dye, T.D.V. (2018). Considering parental hearing status as a social determinant of deaf population health: Insights 
from experiences of the "dinner table syndrome". PLoS ONE 13 (9): e0202169. https://doi.org/10.1371/journal.pone.0202169

Hayes, S. C. (1993). Analytic Goals and the Varieties of Scientific Contextualism: The Varieties of Scientific Contextualism. Reeno: Context Press.

Hayes, S. C., Barnes-Holmes, D., \& Roche, B. (Eds.). (2001). Relational Frame Theory: A Post-Skinnerian account of human language and cognition. New York: Plenum Press.

Iwakabe, S. (2005). Pragmatic meta-analysis of case studies. Annual Progress of Family Psychology, 23, 154-169. doi: 10.1080/09687760802315879

Iwakabe, S., \& Gazzola, N. (2009). From single-case studies to practice-based knowledge: Aggregating and synthesizing case studies. Psychotherapy Research Methods, 19 (4-5), 601-611. doi: 10.1080/10503300802688494.

Joint Commissioning Panel for Mental Health \& SignHealth (2017). Guidance for commissioners of primary care mental health services for deaf people. Retrieved from https://www.jcpmh.info/wp-content/uploads/jcpmh-deaf-guide.pdf

Jupp, V. (1989). Methods of criminological research. London: Unwin Hyman.

Kaiser-Grodecka, I., \& Cieszynska, J. (1991). The understanding of time by deaf pupils. In D. S. Martin (Ed.), Advances in cognition, education, and deafness (pp. 201-204). Washington, DC: Gallaudet University Press.

Kapborg, I. (2000). The nursing education programme in Lithuania: Voices of student nurses. Journal of Advanced Nursing, 32(4), 857-863. Doi: 10.1046/j.13652648.2000.01549.x

Kelly, L. (2017). Silent punishment: The experiences of d/Deaf prisoners (Unpublished Doctoral dissertation). University of Central Lancashire, Lancashire. 
Kelly, L. (2018). Sounding out d/Deafness: The experiences of d/Deaf prisoners. Journal of Criminal Psychology, 8(1), 20-23. ISSN 2009-3829

Kelly-Corless, L. (2019). Delving into the unknown: An experience of doing research with d/Deaf prisoners. Qualitative Inquiry, 1-14. doi: 10.1177/1077800419830133

Kent, G., \& Wahass, S. (1996). The content and characteristics of auditory hallucinations in Saudi Arabia and the UK: A cross-cultural comparison. Acta Psychiatrica Scandinavica, 94(6), 433-7. doi:10.1111/j.1600-0447.1996.tb09886.x

Kim, K.L., Li, D., Jiang, Z., Cui, X., Lin, L., Kang, J.J., .... Kim, C.K. (1993). Schizophrenic delusions among Koreans, Korean-Chinese and Chinese: A transcultural study. The international Journal of Social Psychiatry, 39 (3), 190199. https://doi.org/10.1177/002076409303900305

King, N. (2004). Using templates in the thematic analysis of text. In C. Cassell \& G. Symon (Eds.), Essential guide to qualitative methods in organizational research (pp. 257-270). London, UK: Sage.

Kitson, N., Fernando, J., \& Douglas, J. (2000). Psychotherapy. In P. Hindley \& N. Kitson (Eds.), Mental health and deafness. London: Whurr Publishers, Ltd.

Keulen- de Vos, M. E., Bernstein, D. P., Vanstipelen, S., Vogel, V., Lucker, T. P., Slaats, M. , Hartkoorn, M. and Arntz, A. (2016). Schema modes in criminal and violent behaviour of forensic cluster B PD patients: A retrospective and prospective study. Legal and Criminological Psychology, 21, 56-76. doi:10.1111/lcrp.12047

Lane, H. (1992). The mask of benevolence: Disabling the deaf community. New York: Dawnsign Press.

Laroi, F., Luhrmann, T. M., Bell, V., Christian, W. A., Deshpande, S., Fernyough, C., ... Woods, A. (2014). Culture and hallucinations: Overview and future directions. Schizophrenia Bulletin, 40(4), S213- S220. https://doi.org/10.1093/schbul/sbu012 
Lataster, T., van Os, J., Drukker, M., Henquet, C., Feron, F., Gunther, N., \& MyinGermeys, I. (2006). Childhood victimisation and developmental expression of nonclinical delusional ideation and hallucinatory experiences: Victimisation and non-clinical psychotic experiences. Social Psychiatry and Psychiatric Epidemiology, 41, 423-428. https://doi.org/10.1007/s00127-006-0060-4

Maher, B., \& Spitzer, M. (1993). Delusions. In P. Sutker \& H. Adams (Eds.), Comprehensive handbook of psychology (pp. 263-293). New York: Plenum Press.

Mappin, L., Dawson, D. L., Gresswell, D. M., \& Beckley, K. (2013). Female-perpetrated intimate partner violence: An examination of three cases using multiple sequential functional analysis. Criminal Behaviour and Mental Health, 23(4), 290-303. doi:10.1002/cbm.1874

Marcowicz, H., \& Woodward, J. (1982). Language and the maintenance of ethnic boundaries in the Deaf community. In J. Woodward (Ed.), How you gonna get to heaven if you can't talk with Jesus: On depathologizing deafness (pp. 3-19), Silver Springs: T. J. Publishers.

Marschark, M., Lang, H. G., \& Albertini, J. A. (2002). Educating deaf students: From research to practice. New York: Oxford University Press.

McCulloch, D. (2010). Not hearing us: An exploration of the experience of deaf prisoners in Anglo Welsh prisons A report for the Howard league for penal reform, London: The Howard league for penal reform.

Mitchell, J., \& Vierkant, A. D. (1989). Delusions and hallucinations as a reflection of the subcultural milieu among psychotic patients of the 1930s and 1980s. The Journal of Psychology, 123(3), 269-74. doi:10.1080/00223980.1989.10542981

Mitchell, T. R., \& Braham, L. G. (2011). The psychological treatment needs of deaf mental health patients in high-secure settings: A review of the literature. 
International Journal of Forensic Mental Health, 10(2), 92-106. Doi:

$10.1080 / 14999013.2011 .577135$

Moore, K. (2016). Defining and measuring adaptive behaviour in deaf adults (Unpublished Doctoral dissertation). University of Nottingham, Nottingham.

Munoz-Baell, I. M., \& Ruiz, M. T. (2000). Empowering the deaf: Let the deaf be deaf. Journal of Epidemiological Community Health, 54, 40-44.

O'Rourke, S. \& Grewer, G. (2005). Assessment of Deaf people in forensic mental health settings: A risky business! Journal of Forensic Psychiatry \& Psychology, 16(4), 671-684. doi: 10.1080/14789940500279877

Pakulski, L., \& Kaderavek, J. (2001). Narrative production by children who are deaf or hard of hearing: The effect of role-play. Volta Review, 10(3): 127-139.

Pavlish, C. (2005). Action responses of Congolese refugee women. Journal of Nursing Scholarship, 37(1), 10-17. https:// doi/pdf/10.1111/j.1547-5069.2005.00010.x

Pedersen, N., \& Nielsen, R. (2013). Auditory hallucinations in a Deaf patient: A case report. Case Reports in Psychiatry, 2013, 659698.

http://doi.org/10.1155/2013/659698

Selten, J. P., \& Cantor-Graae, E. (2005). Social defeat: Risk factor for schizophrenia? British Journal of Psychiatry, 187, 101- 102. https://doi.org/10.1192/bjp.187.2.101

Schonaeur, K., Achtergarde, D., Gotthrdt, U., \& Folkerts, H.W. (1998). Hallucinatory modalities in prelingually deaf schizophrenic patients: A retrospective analysis of 67 cases. Acta Psychiatrica Scandinavica, 98, 377-383. Doi: 10.1111/j.16000447.1998.tb10102.x.

Skinner, B.F (1957). Verbal Behaviour. London: Appleton- Century- Croft.

Skinner, B. F. (1974). About behaviorism. New York: Knopf. 
Sommer, I., Roze, C., Linszen, M., Somers, M., \& Van Zanten, G (2014). Hearing loss: The neglected risk factor for psychosis. Schizophrenia Research, 158(1-3), 266-26. https://doi.org/10.1016/j.schres.2014.07.020

Squires, A. (2009). Methodological challenges in cross-language qualitative research: A research review. International Journal of Nursing Studies, 46(2), 277-287. doi: 10.1016/j.ijnurstu.2008.08.006

Stefanis, N., Thewissen, V., Bakoula, C., van Os, J., \& Myin-Germeys, I. (2006). Hearing impairment and psychosis: A replication in a cohort of young adults. Schizophrenia Research, 85, 266-72. https://doi.org/10.1016/j.schres.2006.03.036

Steinberg, A.G., Sullivan, V.J., and Loew, R.C. (1998). Cultural and linguistic barriers to mental health service access: The deaf consumer's perspective. The American Journal of Psychiatry, 155, 982-984. https://doi.org/10.1176/ajp.155.7.982

Stompe, T., Karakula, H., Rudalevičiene, P., Okribelashvili, N., Chaudhry, H., Idemudia, E., \& Gscheider, S. (2006). The pathoplastic effect of culture on psychotic symptoms in schizophrenia. World Cultural Psychiatry Research Review, 1, 157163. Retrieved from: https://www.researchgate.net/profile/Hanna_KarakulaJuchnowicz/publication/228477628_The_pathoplastic_effect_of_culture_on_psych otic_symptoms_in_schizophrenia/links/00b4952cb38e3d4cdc000000/Thepathoplastic-effect-of-culture-on-psychotic-symptoms-in-schizophrenia.pdf

Strauss, J.S. (1991). The person with delusions. British Journal of Psychiatry, 159, 57-62. http://dx.doi.org/10.1192/bjp.159.6.882a

Sturmey, P. (1996). Functional analysis in clinical psychology. Chichester, England: John Wiley \& Sons.

Sturmey, P. (2008). Behavioral case formulation and intervention: A functional analytic approach. Chichester, England: Wiley-Blackwell. 
Thewissen, V., Myin-Germeys, I., Bentall, R., de Graaf, R., Vollebergh, W., \& van Os, J. (2005). Hearing impairment and psychosis revisited. Schizophrenia Research, 76(1), 99-103. https://doi.org/10.1016/j.schres.2004.10.013

Thompson, A. D., Nelson, B., Yeun, H. P., Lin, A., Ammingel, G. P., McGorry, P. D., ... Yung, A. R. (2014). Sexual trauma increases the risk of developing psychosis in an ultra high-risk "prodromal" population. Schizophrenia Bulletin, 40(3), S697-S706. doi: $10.1093 /$ schbul/sbt032

Twinn, S. (1997). An exploratory study examining the influence of translation on the validity and reliability of qualitative data in nursing research. Journal of Advanced Nursing, 26, 418-423.

Valentine, G., \& Skelton, T. (2007). Re-defining 'norms': D/deaf young people's transition to independence. The Sociological Review, 55(1), 104-123. https://doi.org/10.1111/j.1467-954X.2007.00684.x

Veiling, W. A., Selten, J. P., Veen, N. D., Laan, W., Blom, J. D., \& Hoek, H.W. (2006). Incidence of schizophrenia among ethnic minorities in the Netherlands: A fouryear first-contact study. Schizophrenia Research, 86, 189- 193. https://doi.org/10.1016/j.schres.2006.06.010

Vernon, M., \& Andrews, J. F. (1990). The psychology of deafness. New York: Longman. Webb, E. (1966). Unconventionality, triangulation and inference. Princeton NJ: Educational Testing Service.

Weiler, C., Landsberger, S.A., \& Diaz, D.R. (2013). Differential diagnosis of psychosis in a Deaf inpatient with language dysfluency: A case report. Clinical Schizophrenia and Related Psychoses, 7(1), 42-45. Doi: 10.3371/CSRP.WELA.032513. 
Woo, H., \& Twinn, S. (2004). Health needs of Hong Kong Chinese pregnant adolescents. Journal of Advanced Nursing, 45(6), 595-602. https://doi.org/10.1046/j.1365$\underline{2648.2003 .02951 . \mathrm{x}}$

Yamada, A. M., Barrio, C., Morrison, S. W., Sewell, D., \& Jeste, D. V. (2006). Crossethnic evaluation of psychotic symptom content in hospitalized middle-aged and older adults. General Hospital Psychiatry, 28(2), 161-168. doi: 10.1016/j.genhosppsych.2005.12.003

Young, A., Monteiro, B., \& Ridgeway, S. (2000). Deaf people with mental health needs in the criminal justice system: A review of the UK literature. Journal of Forensic Psychiatry, 11(3), 556-570.

Zubin, J., Magaziner, J., \& Steinhauer, S. R. (1983). The metamorphosis of schizophrenia: From chronicity to vulnerability. Psychological Medicine, 13, 551-571. https://doi.org/10.1017/S003329170004798X

Zubin, J., \& Spring, B. (1977). Vulnerability: A new view of schizophrenia. Journal of Abnormal Psychology, 86, 103-126. http://dx.doi.org/10.1037/0021-

$\underline{843 X .86 .2 .103 .}$. 
Tables 
Table 1. Participants' demographic information

\begin{tabular}{|c|c|c|c|}
\hline & Ben $^{\mathrm{a}}$ & Michael & Aiden \\
\hline Age (years) & 51 & 38 & 37 \\
\hline Deafness & $\begin{array}{l}\text { Profound bilateral deafness diagnosed aged } 2 \\
\text { years secondary to meningitis. }\end{array}$ & $\begin{array}{l}\text { Profound bilateral deafness identified aged } 3 \\
\text { years. }\end{array}$ & $\begin{array}{l}\text { Profound pre-lingual bilateral deafness } \\
\text { diagnosed aged } 2 \text { years. Fitted with a cochlear } \\
\text { implant aged } 12 \text { years; stopped wearing the } \\
\text { external piece to aged } 22 \text { years. }\end{array}$ \\
\hline Language & $\begin{array}{l}\text { Primary language is BSL- first learned at } \\
\text { school aged } 5 \text { years. }\end{array}$ & $\begin{array}{l}\text { Primary language is BSL- learned in } \\
\text { residential care aged 3-6 years. }\end{array}$ & $\begin{array}{l}\text { Communicates using BSL in addition to lip- } \\
\text { reading/ speech. }\end{array}$ \\
\hline Diagnosis & Paranoid schizophrenia & Schizoaffective disorder- manic type & Paranoid schizophrenia \\
\hline $\begin{array}{l}\text { Reported } \\
\text { Hallucinations }\end{array}$ & $\begin{array}{l}\text { Voices inside head and emanating from } \\
\text { stomach. Hearing keys inside his head; when } \\
\text { he was in prison reported hearing keys being } \\
\text { jangled in a teasing manner- although he } \\
\text { described he could 'feel' the keys rather than } \\
\text { hearing them, and so no auditory experiences } \\
\text { reported. }\end{array}$ & $\begin{array}{l}\text { Voices, visual hallucinations of moving } \\
\text { pictures related to religion and god, and a } \\
\text { visual hallucination of a face. Hallucinations } \\
\text { were reported to be feelings or images, not } \\
\text { auditory hallucinations of voices. }\end{array}$ & $\begin{array}{l}\text { Voices, screeching noises, and visual } \\
\text { hallucinations of distorted shapes and spirits. }\end{array}$ \\
\hline $\begin{array}{l}\text { Reported } \\
\text { Delusions }\end{array}$ & $\begin{array}{l}\text { No specific delusional content reported beyond } \\
\text { paranoia. }\end{array}$ & $\begin{array}{l}\text { Being paranoid that people were colluding } \\
\text { against him, delusions of grandiosity related } \\
\text { to becoming a professional wrestler, being } \\
\text { famous and writing a book or being on T.V. }\end{array}$ & $\begin{array}{l}\text { Being paranoid, specifically related to being } \\
\text { followed, targeted by homosexuals, and a } \\
\text { government conspiracy to control him via his } \\
\text { cochlear implant. Delusions of grandiosity } \\
\text { concerning scientific inventions and being a } \\
\text { model. }\end{array}$ \\
\hline Index Offence & $\begin{array}{l}\text { Attempted murder and robbery possessing a } \\
\text { firearm. }\end{array}$ & $\begin{array}{l}\text { Manslaughter (due to diminished } \\
\text { responsibility) and grievous bodily harm. }\end{array}$ & $\begin{array}{l}\text { Attempts to make explosives with intent to } \\
\text { bomb the audiology department. }\end{array}$ \\
\hline $\begin{array}{l}\text { Institutional } \\
\text { History }\end{array}$ & $\begin{array}{l}\text { Forensic history including previous prison } \\
\text { sentences. Has been within secure psychiatric } \\
\text { services for the last } 25 \text { years, following his } \\
\text { index offence. At the time of the data }\end{array}$ & $\begin{array}{l}\text { Has been detained in secure psychiatric } \\
\text { services for } 21 \text { years following his index } \\
\text { offence. At the time of data collection, there } \\
\text { was no plan for transition to low secure. }\end{array}$ & $\begin{array}{l}\text { Has been detained in secure psychiatric } \\
\text { services for } 13 \text { years following his index } \\
\text { offence. At the time of data collection, there } \\
\text { was no plan for transition to low secure. }\end{array}$ \\
\hline
\end{tabular}


collection, had declined a transition to low secure services.

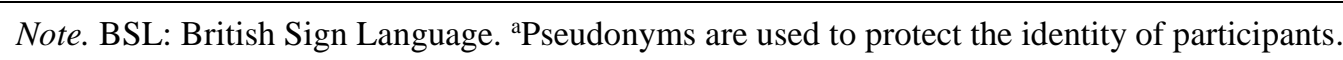


Table 2. Summary of documents reviewed in the file review

\begin{tabular}{lll}
\hline Ben & Michael & Aiden \\
\hline CPA $^{\mathrm{a}}$ reports (12) & CPA reports (14) & CPA reports (8) \\
Nurses reports (6) & Nurses reports (5) & Nurses report (4) \\
Risk assessments (HCR-20 V3) ${ }^{\mathrm{b}}(2)$ & Risk assessments (HCR-20 V3) (2) & Risk assessments (HCR-20 V3) (2) \\
Psychology reports (9) & Psychology reports (11) & Psychology reports (9) \\
Psychiatric reports (6) & Psychiatric reports (8) & Psychiatric reports (7) \\
Tribunal report (2) & Psychiatric discharge summary (1) & Tribunal report (1) \\
Social inquiry report (1) & Inquiry report (1) & Case summary (1) \\
Positive Behaviour Support plan (1) & & \\
\hline
\end{tabular}

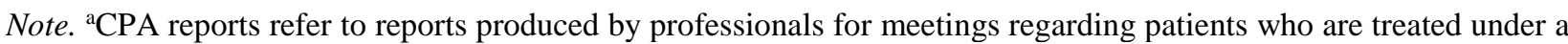
Care Program Approach (CPA). ${ }^{\text {b}}$ The Historical Clinical Risk Management-20, Version 3 (HCR- 20 V3; Douglas, et al., 2013) is a structured risk assessment of historic, current, and future risk of violence. 
Table 3. Functional analysis sequence ONE: School

\begin{tabular}{|c|c|c|}
\hline Ben & Michael & Aiden \\
\hline $\begin{array}{l}\text { Antecedents } \\
\text { Attends Deaf residential school aged } 5 \text { years. Struggles in the } \\
\text { oral classes and is placed in the remedial (sign-based) class. } \\
\text { Is exposed to communication and interaction with deaf } \\
\text { children for the first time. }\end{array}$ & $\begin{array}{l}\text { Attends Deaf residential school. Is placed in a } \\
\text { unit for profoundly deaf children but the other } \\
\text { students also have physical difficulties. }\end{array}$ & $\begin{array}{l}\text { Attends mainstream schools with support. Is bullied } \\
\text { by hearing peers at school who call him "Deaf } \\
\text { lugs". Only friends at school are the other two deaf } \\
\text { children. }\end{array}$ \\
\hline $\begin{array}{l}\text { Behaviours } \\
\text { Covert: Belief that it is unfair that he has to attend a } \\
\text { residential school due to being deaf and that he is treated } \\
\text { differently to his hearing siblings. Sense of helplessness } \\
\text { about being sent away; 'I am deaf that is just the way it is'. } \\
\text { Feels powerless. Views signing as inferior and associated } \\
\text { with stupidity. }\end{array}$ & $\begin{array}{l}\text { Behaviours } \\
\text { Covert: Feels upset that he has to go away to } \\
\text { school and his siblings did not because they } \\
\text { were hearing. Feels unequal to his siblings. He } \\
\text { is confused at school and worries the other } \\
\text { students are colluding against him. Does not } \\
\text { want to be seen as a deaf boy, he wanted to be } \\
\text { like 'ordinary boys'. }\end{array}$ & $\begin{array}{l}\text { Behaviours } \\
\text { Covert: Feels different and does not feel accepted in } \\
\text { hearing environments. Enjoys being able to talk to } \\
\text { his deaf friends and not missing out on } \\
\text { conversations but resents only being able to make } \\
\text { friends with the other deaf children and thinks they } \\
\text { are "a bit thick". }\end{array}$ \\
\hline $\begin{array}{l}\text { Overt: He establishes a role as being mischievous at school, } \\
\text { increasing his social interactions with peers. He starts } \\
\text { misbehaving, such as writing on the board. In contrast, he } \\
\text { withdraws and isolates himself when at home, spending } \\
\text { increasingly more time in his bedroom. }\end{array}$ & $\begin{array}{l}\text { Consequences } \\
\text { The language barrier between Michael and his } \\
\text { family increases, his family cannot }\end{array}$ & $\begin{array}{l}\text { Consequences } \\
\text { Extra science activities remove opportunities to be } \\
\text { bullied. }\end{array}$ \\
\hline $\begin{array}{l}\text { Key Learning } \\
\text { - Life is unfair (being treated differently to siblings) } \\
\text { - Signing is inferior to oral communication; signing means } \\
\text { I am less able. } \\
\text { - Getting attention from being in trouble is better than } \\
\text { nothing. } \\
\text { - Hearing people have it easy. }\end{array}$ & $\begin{array}{l}\text { Key Learning } \\
\text { - Life is unfair (being treated differently to } \\
\text { siblings). } \\
\text { Other deaf children are disabled, being with } \\
\text { other deaf children risks being seen as } \\
\text { disabled. } \\
\text { - To be deaf is to be inferior and unequal. } \\
\text { Being deaf means being different, including } \\
\text { from family. }\end{array}$ & $\begin{array}{l}\text { Key learning } \\
\text { - To be deaf is to be different. } \\
\text { - Being with hearing children risks being bullied } \\
\text { and rejected. } \\
\text { - Being with other deaf children risks being seen } \\
\text { as stupid. } \\
\text { - Science keeps me safe. }\end{array}$ \\
\hline
\end{tabular}

- Hearing people have it easy.

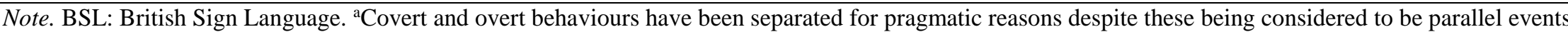

(Skinner, 1974). The presented order does not suggest any causality or that internal events are separate to external events. 
Table 4. Functional analysis sequence TWO: Early onset of psychosis

\begin{tabular}{|c|c|c|}
\hline Ben & Michael & Aiden \\
\hline $\begin{array}{l}\text { Antecedents } \\
\text { Isolated in prison and not provided with } \\
\text { communication support. }\end{array}$ & $\begin{array}{l}\text { Antecedents } \\
\text { Witnesses a car of "youths" attempt to run over his } \\
\text { brother. }\end{array}$ & $\begin{array}{l}\text { Antecedents } \\
\text { Is asked to leave the audiology department when they } \\
\text { are unable to see him without an appointment. }\end{array}$ \\
\hline $\begin{array}{l}\text { Behaviours } \\
\text { Covert: Onset of voices that are experienced as } \\
\text { powerful, strong, angry, and horrible towards him } \\
\text { (teasing him), emanating from his stomach. Believes } \\
\text { the voices were prison officers telling him that he is } \\
\text { "bad" and that "they do not like him". Feels paranoid. } \\
\text { Is fed up of being in prison but feels safer in prison } \\
\text { than in the community. } \\
\text { Overt: Establishes coping strategies whereby he } \\
\text { shouts back and swears at the voices, breaks things, } \\
\text { and bangs his head. Attempted to spit the voices out. } \\
\text { Informs professionals he is feeling isolated. } \\
\text { Consequences } \\
\text { Distress is reduced through coping strategies. Referral } \\
\text { to psychiatry. Receives poor communication support. } \\
\text { Key Learning } \\
\text { It is not worth asking for help it will not be } \\
\text { provided. } \\
\text { Others will not adapt, deaf people are expected to } \\
\text { adapt for hearing people. } \\
\text { The world is a lonely place if you are deaf. } \\
\text { Coping strategies (banging head etc.) can help } \\
\text { reduce negative feelings. }\end{array}$ & $\begin{array}{l}\text { Behaviours } \\
\text { Covert: Becomes very upset, anxious and 'paranoid' } \\
\text { about people. Feelings of 'powerlessness of being } \\
\text { able to retaliate'. Wishes to succeed and believes } \\
\text { wrestling will help him achieve success. } \\
\text { Overt: Withdraws, locks himself in bedroom, and } \\
\text { watches an increasing amount of wrestling. Goes to a } \\
\text { wrestling event with a packed bag and an out-of-date } \\
\text { passport, in an attempt to convince the wrestlers to } \\
\text { take him to the USA to become a wrestler. When sent } \\
\text { home by security he blames his parents and throws a } \\
\text { brick through the window of his family home. } \\
\text { Consequences } \\
\text { Is arrested and admitted to a psychiatric hospital. } \\
\text { Key Learning } \\
\text { - The world is a scary place. } \\
\text { - Others prevent possibilities for success. }\end{array}$ & $\begin{array}{l}\text { Behaviours } \\
\text { Covert: Feels angry that the audiology department } \\
\text { did not help him. Delusional belief that the } \\
\text { government want to control him through his cochlear } \\
\text { implant. Believes 'Society isn't treating me right' and } \\
\text { thinks that 'if I blow up the implant service people } \\
\text { will know I want my implant out'. } \\
\text { Overt: Stops using his implant completely. Attempts } \\
\text { to make a bomb in his bedroom. } \\
\text { Consequences } \\
\text { Is arrested and admitted to a psychiatric hospital. } \\
\text { Key learning } \\
\text { - It is not worth asking for help, it will not be } \\
\text { provided. } \\
\text { - Violence is the only way to be heard. } \\
\text { Society is against deaf people. }\end{array}$ \\
\hline
\end{tabular}

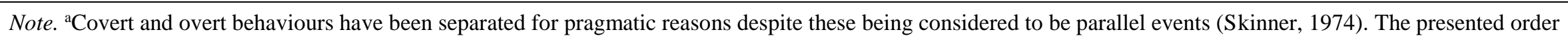
does not suggest any causality or that internal events are separate to external events. 
Table 5. Functional analysis sequence THREE: Offence behaviours

\begin{tabular}{|c|c|c|}
\hline Ben $^{b}$ & Michael & Aiden $^{c}$ \\
\hline $\begin{array}{l}\text { Behaviours } \\
\text { Covert: He feels frustrated and hopeless due to lack } \\
\text { of support and low income, attributes this to being } \\
\text { deaf and believes that deaf people cannot get good } \\
\text { jobs, this is 'unfair' and deaf people are } \\
\text { disadvantaged. } \\
\text { Overt: He is passive about his circumstances; he does } \\
\text { not seek help or complain about the lack of support } \\
\text { and discrimination experienced in finding } \\
\text { employment. He begins to drink heavily. He commits } \\
\text { four attempted bank robberies. } \\
\text { Consequences } \\
\text { He initially receives a suspended sentence for two } \\
\text { attempted robberies which he breaches the conditions } \\
\text { of with a further two attempted robberies and is } \\
\text { arrested and starts a six year prison sentence. } \\
\text { Key Learning } \\
\text { - Being deaf means having low income jobs. } \\
\text { - Strengthened sense that hearing people have it easy. } \\
\text { - Committing robberies can provide money. } \\
\text { - Consolidated learning that when people cannot } \\
\text { support him he is sent away. }\end{array}$ & $\begin{array}{l}\text { Behaviours } \\
\text { Covert: His paranoid delusional beliefs about others } \\
\text { targeting him increase, he believes people are } \\
\text { gossiping about him and that it is Miss X's son who is } \\
\text { responsible for spreading rumours. He experiences } \\
\text { the onset of voices and experiences paranoia related } \\
\text { to the voices. } \\
\text { Overt: He leaves to stay at a friend's empty flat on his } \\
\text { own for a short period to avoid mental health services } \\
\text { and alcohol intake increases. He goes back to Miss } \\
\text { X's flat to confront her son but murders Miss X when } \\
\text { he gets there. } \\
\text { Consequences } \\
\text { Is arrested and admitted to a psychiatric hospital and } \\
\text { crime receives a lot of media attention. } \\
\text { Key Learning } \\
\text { Committing a serious crime can get a lot of } \\
\text { attention from the news; people are interested in } \\
\text { me now. } \\
\text { If I have no control then others are responsible } \\
\text { and to blame for what I have done. }\end{array}$ & $\begin{array}{l}\text { Antecedents } \\
\text { Is asked to leave the audiology department when they } \\
\text { are unable to see him without an appointment. } \\
\text { Behaviours } \\
\text { Covert: Feels angry that the audiology department did } \\
\text { not help him. Delusional belief that the government } \\
\text { want to control him through his cochlear implant. } \\
\text { Believes 'Society isn't treating me right' and thinks } \\
\text { that 'if I blow up the implant service people will } \\
\text { know I want my implant out'. } \\
\text { Overt: Stops using his implant completely. Attempts } \\
\text { to make a bomb in his bedroom. } \\
\text { Consequences } \\
\text { Is arrested and admitted to a psychiatric hospital. } \\
\text { Key learning } \\
\text { - It is not worth asking for help, it will not be } \\
\text { provided. } \\
\text { - Violence is the only way to be heard. }\end{array}$ \\
\hline
\end{tabular}




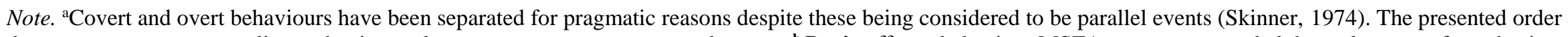
does not suggest any causality or that internal events are separate to external events. ${ }^{\mathbf{b}}$ Ben's offence behaviour MSFA sequence preceded the early onset of psychosis

MSFA sequence chronologically. 'Only included for comparative purposes. Aiden's offence behaviour sequence is presented in the early onset of psychosis MSFA

(Table 5) due to the offence being committed at this stage.

Table 6. Functional analysis sequence FOUR: Experiences of secure psychiatric services

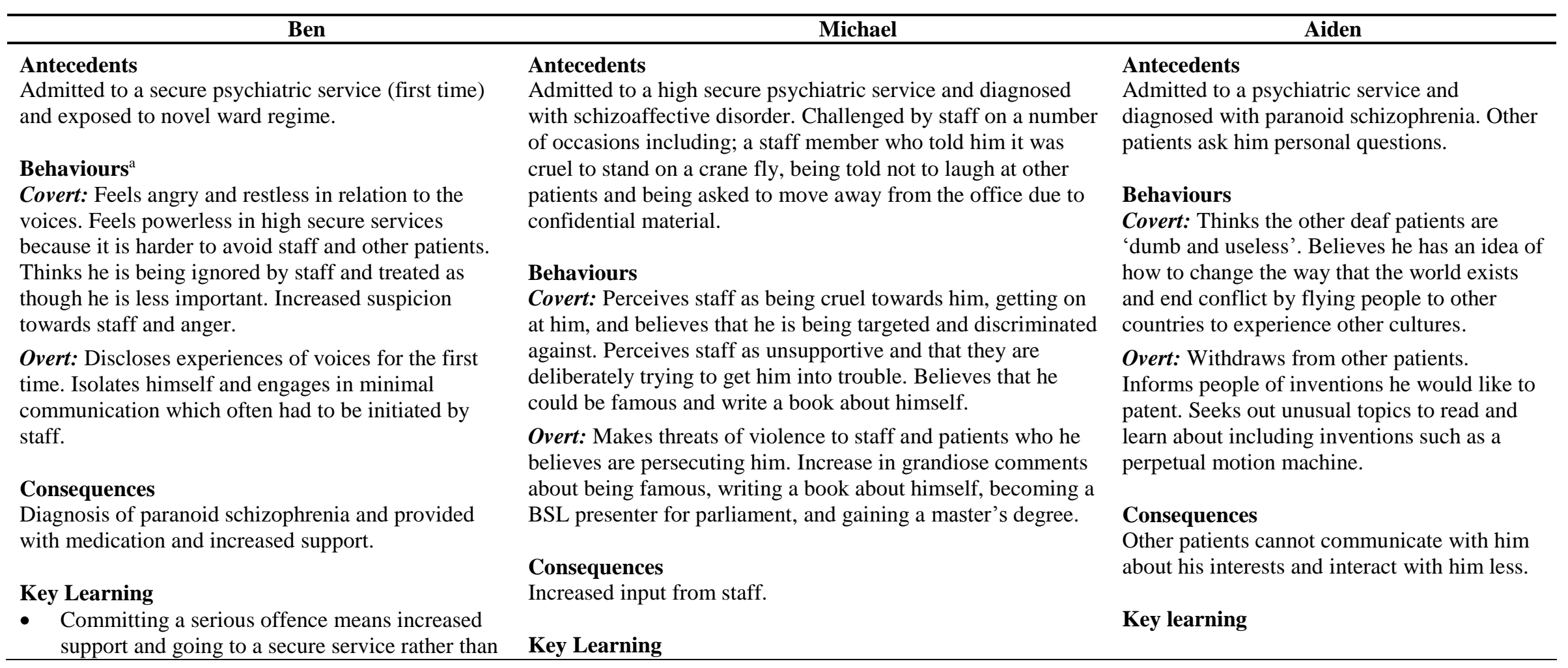


prison as he had following previous offenses

that had not resulted in harm to others

- Telling professionals about voices leads to medication.
- Others prevent possibilities for success.

- It is not worth asking for help but being aggressive gets more support.
- $\quad$ Being deaf risks being seen as stupid and less able.

- Knowledge about science that others do not understand means intelligence and prevents being seen as stupid.

- Interest in science and unusual topics keeps other patients away.

Note. BSL: British Sign Language. ${ }^{\mathrm{a} C o v e r t}$ and overt behaviours have been separated for pragmatic reasons despite these being considered to be parallel events (Skinner, 1974). The presented order does not suggest any causality or that internal events are separate to external events. 
Table 7. Themes derived from a Thematic Analysis of the Sequential Functional Analysis sequences generated across all three cases

\begin{tabular}{|c|c|c|}
\hline Theme & Subthemes & Description \\
\hline $\begin{array}{l}\text { Acceptance of } \\
\text { Deafness as a } \\
\text { negative state }\end{array}$ & $\begin{array}{l}\text { Sense of powerlessness } \\
\text { Learned helplessness }\end{array}$ & $\begin{array}{l}\text { This theme concerns the sense of powerlessness } \\
\text { experienced by all participants due to limited } \\
\text { control in their lives and limited opportunities to } \\
\text { express their needs. This influenced a sense of } \\
\text { learned helplessness. }\end{array}$ \\
\hline $\begin{array}{l}\text { Caught between } \\
\text { two worlds }\end{array}$ & $\begin{array}{l}\text { Rejection } \\
\text { Misfit } \\
\text { Identity conflict } \\
\text { Membership to the Deaf } \\
\text { community }\end{array}$ & $\begin{array}{l}\text { This theme reflects the participants' conflict about } \\
\text { where they belong in their family, hearing and deaf } \\
\text { groups, and wider society. This theme also reflected } \\
\text { experiences of being perceived as different to } \\
\text { others and their own rejection/ acceptance of } \\
\text { deafness. }\end{array}$ \\
\hline $\begin{array}{l}\text { Deaf-specific } \\
\text { Victimisation }\end{array}$ & $\begin{array}{l}\text { Deaf versus hearing } \\
\text { Disadvantaged } \\
\text { Discriminated } \\
\text { Injustice } \\
\text { Inequality/ inferiority } \\
\text { Lack of support }\end{array}$ & $\begin{array}{l}\text { This theme concerns negative experiences of } \\
\text { discrimination and being discriminated against by } \\
\text { individuals, organisations, and the wider society } \\
\text { due to their deafness, for example with regards to } \\
\text { barriers to accessing equal services to hearing } \\
\text { peers. }\end{array}$ \\
\hline $\begin{array}{l}\text { General } \\
\text { Victimisation }\end{array}$ & $\begin{array}{l}\text { Abuse } \\
\text { Bullied } \\
\text { Victimhood } \\
\text { Targeted } \\
\text { Vulnerable } \\
\text { Suspicion }\end{array}$ & $\begin{array}{l}\text { This theme concerns experiences of being bullied, } \\
\text { abused, and a sense of vulnerability related to } \\
\text { participants perceiving themselves as an 'easy } \\
\text { target', not directly linked to their deafness but } \\
\text { because they are perceived as weak. }\end{array}$ \\
\hline Language factors & $\begin{array}{l}\text { Communication barriers } \\
\text { Lack of access } \\
\text { Imposed expectations } \\
\text { Confusion } \\
\text { Shattered expectations }\end{array}$ & $\begin{array}{l}\text { Language factors span communication barriers, } \\
\text { expectations about how they should communicate/ } \\
\text { interact with hearing individuals, and how this } \\
\text { developed a sense of confusion. Participants also } \\
\text { reported 'shattered expectations' about how they } \\
\text { would be able to succeed in a hearing world. }\end{array}$ \\
\hline $\begin{array}{l}\text { Service access } \\
\text { issues }\end{array}$ & & $\begin{array}{l}\text { Service access issues reflect the participants' } \\
\text { experiences of barriers to services from childhood } \\
\text { through to the present, and how the medical model } \\
\text { of forensic services may have impacted on their } \\
\text { development of a framework for understanding } \\
\text { their experiences of hallucinations and delusions. }\end{array}$ \\
\hline $\begin{array}{l}\text { Common } \\
\text { psychosocial } \\
\text { factors }\end{array}$ & $\begin{array}{l}\text { Financial difficulties } \\
\text { Substance use } \\
\text { Lack of support system } \\
\text { Isolation }\end{array}$ & $\begin{array}{l}\text { Common psychosocial factors reflect issues that are } \\
\text { shared psychosocial factors to hearing individuals } \\
\text { and identified stressors from the literature, not } \\
\text { unique to deafness. }\end{array}$ \\
\hline
\end{tabular}

